Community Engagement in a First-Year Engineering Communication Course: Increasing Student Numbers from Handfuls to Hundreds.

Ms. Laura M Patterson, University of British Columbia

Ms. Patterson is a Senior Instructor at the University of British Columbia, Okanagan campus in the School of Engineering. She has taught technical and professional communication to engineering students since 2001. 


\title{
[Work In Progress] Community Engagement in a First-Year Engineering Communication Course: Increasing Student Numbers from Handfuls to Hundreds.
}

\begin{abstract}
Engaging first-year engineering students in their mandatory, first-term, communication course can be a challenge when some may not yet understand how these communication skills will be used in their day-to-day professional interactions. However, adding a real client with real needs where the students' work can have real impact adds immediacy and interest. To those ends, a community service learning team proposal project was created in 2011 for 60 students of a first term, first-year engineering writing course, which is a part of a common first-year engineering curriculum. In this assignment, students had the opportunity to practice the communication skills required for engineering through team fundraising proposals and presentations for local not-for-profit organizations. A proposed idea from one student team was implemented by the community organization the following summer. The not-for-profit used the idea to raise over $\$ 18,000$, and it has since become one of their annual fundraising events.

After the success of the first iteration of the project, it was offered to all 220 incoming first-year engineering students in 2012. The 2012 iteration of the team proposal project marked the first time that an entire cohort of students was able to participate in community service learning in any discipline at that small university campus. The team proposal project was offered again in 2013.

There are multiple considerations for this type of project in terms of logistics and sustainability, especially for yearly participation of 220 students in this project. This paper will discuss the strategies involved in adapting a community service learning project originally designed for 60 students to a larger scale project for 220 students while maintaining the academic robustness of the proposal assignment and the good will of the partnering community organizations.
\end{abstract}

\subsection{Introduction}

Engineering is a profession that holds high respect within the community. The design, communication, research, audience analysis, and business skills that engineers build and develop throughout their careers are invaluable to other not-for-profit organizations to solve their challenges. In fact, it is an engineer's obligation "to serve humanity" and share their skills "without reservation for the public good."

Service learning has been implemented as a pedagogical strategy in technical communication classes for engineering students. In the context of first-year engineering curriculum, service learning is a useful pedagogical strategy that integrates community engagement with classroom activities and critical reflection in order to engage students in their obligations as global citizens early on in their education. In particular, the experiential aspect of service learning engages these new students in the complexity and uncertainty of real-world problems they will inevitably face in the future. 
To understand the choices made in this project, it is necessary to understand the circumstances surrounding the course itself. The engineering curriculum at the School of Engineering in the Faculty of Applied Science at the University of British Columbia, Okanagan campus features common first- and second-year course scheduling. In the first term of the first year, the students have APSC 176: Engineering Communication.

APSC 176: Engineering Communication is mandatory for first-year engineering students. There are between 7-8 sections that run every year in the fall term for approximately 200-220 students. As a result, there are 3-4 instructors of the course at any given time. The author is a tenured senior instructor who regularly teaches the course and coordinates sessional instructors of the course. There is another tenured senior instructor who regularly teaches the course and has participated in the project in the 2013 iteration of it. She was seconded for two years while the project began and has been heavily supportive of it; however, she has projects she would like to try in her own sections that might make participation in future iterations of the CSL project challenging. The question of sustainability of the large-scale project is not just dependant on the organizations, but also on cooperation of other instructors in a multi-sectioned course.

Service learning is an upcoming trend in engineering education ${ }^{2}$. It is highly regarded for its abilities to promote ideas of civic responsibility, community engagement, and humanitarianism necessary in such a highly regarded profession ${ }^{3}$. While often reserved for upper-year design classes $^{2}$, it has also been integrated into first-year engineering curriculum ${ }^{2,4-6}$. This adds engagement of students and gives them a taste of working with real "clients". While often a part of design courses, many implementations either tie in the communication courses, or have the service learning aspect solely reside within the communication course. For example, Fontenot and Chandler describe the implementation of service learning in an engineering communication course at Texas Tech University, where students present designs to public schools and found it pedagogically successful ${ }^{4}$. Flammia ${ }^{7}$ noted that students benefited academically while "fostering their sense of civic responsibility." Matthews and Zimmerman ${ }^{8}$ explore the implications of this relationship and the benefits outweighed the challenges in its implementation.

The communication course is an excellent place for service learning to reside because it can engage students in a course that can occasionally confound some science-minded students. Within technical communication pedagogy, Cargile Cook $^{9}$ suggests that students benefit from repeated exposure to projects that challenge students on multiple literacies. Service learning does that by exposing students to audience adaptation, teamwork skills, ethical considerations, and the ideas of service and community. The assignment was intended to blend Cargile Cook's rhetorical literacy of audience adaptation and social literacy of team work in a complex assignment that allowed students to exercise their creativity and ingenuity to solve a real-world problem. Projects like this greatly enhance workplace skills. Cargile Cook asserts that exposing students to these multiple layers of literacy in assignments repeatedly "prepares them for life long learning"9 a challenging graduate attribute to quantify. 
It can be challenging to engage first-year engineering students in their mandatory communication course when they may not yet understand the role of these communication skills in their future professional lives. However, adding an authentic audience can enhance student engagement and help connect the course material to the day-to-day professional interactions of a practicing engineering professional.

The choice to use an authentic audience for the project is based in part on the layered literacies key for technical communication pedagogy discussed by Cargile Cook. In particular, the rhetorical literacy acknowledges the need for a specific audience and situation to guide students' choices in creating a document. The authentic audience allows students to make choices based on relevance. The social literacy is addressed in the team aspect of the assignment. The authentic audience for a team project engages students in the complexity and uncertainty they will experience in real-world engineering problems in the workforce.

With the documented success of such endeavours over the past decade ${ }^{2-8,10}$, it is important to explore strategies to support the sustainability of these projects. Challenges include a high number of students in the program every year and a reasonably finite number of community organizations with finite needs. Once an organization has had a design completed, it no longer has that need. Another limitation is that not all organizations have design needs that engineering students can fulfill. As well, to implement these designs in first-year curriculum, it is important to recognize that first-year students do not yet have design skills to create major solutions to real design needs of clients, though they do have enthusiasm, creativity, and problem-solving skills. The author, a technical communication specialist, and other instructors of the course, also lack the expertise in engineering design to effectively judge such projects.

APSC 176's team proposal project taps into the constant need for funding by not-for-profit organizations and appeals to a wide variety of not-for-profit organizations. Many of these organizations often are highly enthusiastic simply to engage the students to promote awareness of the organizations. Even if the organization does not come away with a concrete product, they have had 220 students exposed to their organization in a more meaningful way than advertising. Awareness is seen by the not-for-profit organizations as a great benefit.

This paper will discuss the strategies involved in expanding a community service learning project from 60 students to 220 students. The expansion of the project was done with the goal of maintaining both the academic robustness of the proposal assignment and the good will of the partnering community organizations.

\subsection{Discussion}

The discussion overviews the assignment and summarizes each iteration of the assignment and the choices made in order to allow for sustainability in the course. The aim here is to elucidate the pedagogical strategies embedded in the process that could be transferable to other institutions to allow for long-term commitment to service learning.

\subsection{The Assignment}


Lima and Oakes ${ }^{10}$ identify the following four key characteristics to effective service learning education: service, academic connection, reciprocal relationship, reflection. With those in mind, the learning objectives for this assignment were created.

The learning objectives were for students to write a problem-solution proposal to a local not-forprofit organization to support and garner funds for an actual engineering/science-related endeavor relevant to the organization. This project is broken up into the following three assignments: the team proposal, the team oral presentation, and the individual written reflection.

In this assignment, students had the opportunity to practice the communication skills required for engineering through team fundraising proposals and presentations for local not-for-profit organizations. Students develop their ability to work on an assigned team, organize a problemsolution argument, conduct research, describe (using numbers) and explain a solution to a realworld problem, and write a persuasive proposal to a specific audience. Students also learn some of the challenges of being creative within real-world constraints, and the importance of being able to write a well-organized, persuasive engineering proposal to a range of audiences. Productive teamwork requires excellent leadership, good conflict resolution skills, and, especially, clear and constant communication between all members. Students learn basic teamwork skills, as they organize the work required for their proposals.

Students benefit from having an authentic audience and learning civic responsibility. Organizations benefit from 2-6 fundraising ideas and increased awareness of the organization and the things that they do within the community. In the final component of the assignment, students reflect on the project, the organization, their writing skills, and how what they learned in the project will be useful in future academic and workplace projects.

The assignment has been executed three times, to a total of nearly 500 first-year engineering students since it began in 2011.

\subsection{The First Iteration}

The first iteration of the Community Service Learning Team Proposal Project (CSLTPP), was created in 2011 for 60 students of a first term, first-year engineering writing course, which is a part of a common first-year engineering curriculum.

The not-for-profit community organizations were contacted through of the University of British Columbia, Okanagan campus's Community Service Learning Program. Several local community organizations had a variety of needs that engineers and their unique skills could serve. Some of these organizations were scientific in nature, some had engineering/science-related problems that engineers could address, and some simply needed the creativity and soft skills engineers possess.

Because of the small number of students involved, it was possible for them to have closer interaction with clients. Student teams met the organization representatives out of class time and at a variety of venues. If an organization had a facility or building, students were able to meet them there. In other instances, when the organizations were run on a shoestring budget and off 
of a representative's front porch (as was the case with one organization who had storage and transportation needs), students were faced with the reality of the organization's situation, which often contradicted students' original impressions. The student teams presented their ideas to the organizations during class time and the organization representatives were present.

The drawback of the small numbers was that each client ended up with only one or two fundraising ideas. These ideas tended to be thoughtful and audience centric since the students had more hands-on experience with the organizations.

Expanding the project from two sections of 60 students in total, to eight sections of 220 students was justified for a two reasons. First, the author was then put in charge of guiding all sessional instructors for all sections of the course. Because the curriculum is common in the first year, it is necessary to have some unity among all sections of the course. To streamline this process, and with an indication of interest of the sessional instructors, it was decided that expanding the project to all sections would be a useful experiment. At that time, the School of Engineering was going through accreditation, and the idea that all first-year students would get a service learning experience was seen as a great way to meet some of the new graduate attributes outlined by the $\mathrm{CEAB}^{11}$.

Anecdotally, the students seemed to engage in the assignment more than the author had seen in past classes. They seemed to achieve the pedagogical goals of the assignment. More definitive answers in terms of whether or not the student experiences reflect the author's anecdotal understanding of their experience are still necessary.

Ultimately, in engineering, the success of a project is based on client experience and pragmatics. Success is determined based on how well clients were ultimately able to fundraise using those ideas or whether or not an idea was implemented by the organization. Demonstrated "success" in terms of client experience has been acknowledged in fundraising ideas being implemented and successfully raising dollars. Given that one idea from the first iteration raised over $\$ 18,000$ in its first run and since has resulted in an annual event that has raised over $\$ 40,000$ for the organization in the last two years, the author considers the first iteration of the assignment a success.

\subsection{The Second Iteration}

After the success of the first iteration of the project, it was offered to all 220 incoming first-year engineering students in 2012. The 2012 iteration of the team proposal project marked the first time that an entire cohort of students was able to participate in community service learning in any discipline at that small university campus. Some of the same organizations returned, but most of the organizations were new to the project.

In order to adjust the project from the one-team-to-one-organization format used in the previous year, a higher ratio of students to organizations was necessary. To accommodate the student numbers, eight organizations were used, and only one team per section was assigned to each organization. It worked out that each organization (depending on the dispersion of students across sections of the course) had 5-6 teams coming up with fundraising ideas for them. The 
major adjustment of having students compete for the best idea for their clients added another level of student engagement. As well, this competition mimics the proposal process that engineers face in the workplace, where clients are presented with several ideas, but only one idea is used.

To avoid overwhelming the organizations with the higher number of students working for them, it was necessary to limit the student interactions with the organization in a more formal setting. A "Meet the Organizations" night was implemented to allow students to interact with their organization representative while preventing organizations from being overwhelmed by student requests. All organizations presented their unique fundraising needs to the whole group, and then the student teams proceeded to breakout spaces to interview the organization representatives on their specific fundraising needs. All subsequent contact with organizations was via email and copied to their section's instructor to ensure that students and representatives remained focussed within the pedagogical limitations of the assignment.

Instead of the in-class presentations, an out-of-class "Team Presentation Night" was organized to allow the students to present to the organization representatives all at once. To accommodate the large numbers, three rooms were used with 2-3 organizations and their corresponding teams per

room. This allowed for students who were spread over a variety of sections to see the competing ideas for their organization as well as be exposed to the unique constraints faced by other organizations. Organizations chose the best presentation, and the winning team received a small mark bonus on their written proposal.

The author deems the second iteration and expansion a success, but it certainly experienced challenges in the process of expanding it to the larger numbers. While the organizations had more good ideas, they didn't feel the quality of these ideas was as good as the first iteration. They requested more evidence of the feasibility of the ideas in terms of prospective budgets and the use of organization resources. The organizations also wanted more interaction with the students and seemed less concerned about negotiating the higher student numbers, though more concrete surveying on this point will clarify within what limitations. Students seemed to like assignment but asked for a few changes for the presentation competition to clarify how the organizations would choose the winner and to limit repetitiveness from listening to multiple teams present similar ideas to the same organization. In terms of client implementation of the ideas, perhaps because the organizations verbalized less satisfaction with the quality of ideas, the organizations have taken elements from several of the ideas presented and added them to existing fundraising events.

\subsection{The Third Iteration}

In September of 2013, the team fundraising proposal project was rolled out again, this time with some adjustments to incorporate the anecdotal feedback received from both students and organizations through action research. Again, there were a few returning organizations and mostly new organizations, and we experimented by including different definitions of not-forprofit organizations beyond charitable, including a sports club and a co-operative member driven organization. 
The general format remained the same as the previous iteration with a "Meet the Organizations Night" and a "Team Presentations Night." To address the organizations' desire to have more interaction with students, we added leniency to the email restrictions and allowed for site visits, if students and organizations wished, though they were not required as they were in the first iteration.

The primary pedagogical focus was increasing the quality of ideas that the students presented to the organizations in order to have something more useful and feasible for them to implement. In order to do this, the assignment needed to focus more on developing and explaining the budget and resources necessary. Also, more in-class guidance on brainstorming and creativity was provided along with additional worksheets and resources. For a course on general academic and research writing skills, additional focus on persuasion, audience adaptation, and evidence use also was implemented in order to ensure higher quality ideas with appropriate, useable, and feasible implementation strategies.

This iteration was much more successful than the second iteration. The not-for-profit organizations still had a variety of ideas, but they seemed pleased with the number of them that they could envision executing right away. One organization took their winning idea and ran it the following month, though the author does not have confirmation on the amount of money they raised. The students seemed pleased, though some indicated that they preferred to focus only on charitable organizations, rather than accommodating the wider definition of not-for-profit.

\subsection{Evaluation Plan}

At the outset of this paper, it was stated that this projects sustainability was contingent on maintaining the academic robustness and good will of partnering organizations. The project has been deemed successful anecdotally; however, these observations need to be tested with surveys and assessment tools to determine if the project achieved its intended purpose and if it had the desired impact. The next phase of the project involves surveying the three major stakeholders in the project: the students, the participating not-for-profit organizations, and the professors involved in delivering the assignment to students. These stakeholder surveys will be to determine if they 1) deemed this a valuable exercise, 2) felt they achieved the major learning goals, and 3) believed this project is worth the effort to execute it. The surveys will be implemented for past involvement, where appropriate, and future iterations of the project. The goals of this survey will be to collect data on student perceptions of the assignment, evaluation of student learning and achievement of learning outcomes, and value to the not-for-profit organizations. In the future, it will be useful to do interview the past participating not-for-profit organizations to understand how the ideas were used and implemented if they were at all.

\subsection{Conclusions}

There are multiple considerations for this type of project in terms of logistics and sustainability, especially for yearly participation of 220 students in this project.

The author found that the key element that allowed flexibility and expansion of this assignment is the universality of fundraising as a way of interesting a wide variety of organizations to 
participate. These organizations are always reliant on fundraising ventures to keep them in operation and unique and feasible ideas are not always easy to create. Because it is not a physical design requirement, first year students can use their ingenuity and creativity to come up with and develop unique and well thought out fundraising ideas for organizations. They also have the opportunity to practice and expand upon audience adaptation and client relations and have a taste of what that is like in a lower stakes situation with a not-for-profit.

Another major consideration in running this assignment on a large scale is the logistics of negotiating relationships with a wide variety of organization representatives. This collaboration has been done through the University of British Columbia, Okanagan campus's Community Service Learning Program and their representatives. This department is available on the Okanagan campus whose mandate it is to liaise between the faculty and the organizations so that it is a rewarding experience for all involved. This service has made running a project with multiple and varied not-for-profit organizations possible.

The third consideration is planning. In order to ensure that a larger-scale project runs as smoothly as possible, much planning needs to happen ahead of time to ensure the multiple working parts of the project operate as seamlessly as possible during the term.

One question of sustainability at this juncture is whether or not other instructors wish to continue with the project. While it has been beneficial to the organizations, and anecdotally the students seemed to have found the project valuable and engaging (though that will be explored more fully in the next iteration of the assignment), this project is time consuming for the instructors of the course.

The next steps for this project are to evaluate the project through the stakeholder surveys to determine if they are satisfied with the results of the project in terms of student experience, pedagogical outcomes, and impact within the community. Also, it would be useful in the long term to implement a large-scale survey of students who have participated in the assignment to see if they use the skills in future assignments.

Ultimately, the expansion of the team proposal project has been a tremendous learning experience in the sustainability of service learning projects.

\section{References}

1. American Society of Civil Engineers (1970). Obligation of the engineer. Retrieved from http://www.asce.org/uploadedFiles/Leadership_Training_-_New/OBLIGATION.pdf

2. Oakes, W. (2009). Creating effective and efficient learning experiences while addressing the needs of the poor: An overview of service-learning in engineering education. Paper presented at the $116^{\text {th }}$ American Society for Engineering Education Annual Conference and Exposition, Austin, TX.

3. Passino, K. M. (2009). Educating the humanitarian engineer. Science and Engineering Ethics, 15. 577-600.

4. Fontenot, A. D. \& Chandler, J. R. (2004) Integrating service learning into engineering communications courses. Paper presented at the $111^{\text {th }}$ American Society for Engineering Education Annual Conference and Exposition, Salt Lake City, UT. 
5. Meadows, L. \& Jarema, S. (2006). An evaluation of the impact of a service learning project in a required firstyear engineering course. Paper presented at the $113^{\text {th }}$ American Society for Engineering Education Annual Conference and Exposition, Chicago, IL.

6. Oakes, W. \& Thompson, M. (2005). Institutionalizing service-learning into a first-year engineering curriculum. Paper presented at the $112^{\text {th }}$ American Society for Engineering Education Annual Conference and Exposition, Portland, OR.

7. Flammia, M. (2011). Using service-learning and global virtual team projects to integrate sustainability into the technical communication curriculum. Paper presented at the IEEE International Professional Communication Conference, Cincinnati, OH.

8. Matthews, C. and Zimmerman, B. B. (1999). Integrating service learning and technical communication: Benefits and challenges. Technical Communication Quarterly. 8. 383-404.

9. Cargile Cook, K. (2002). Layered literacies: A theoretical frame for technical communication pedagogy. Technical Communication Quarterly. 11(1) 5-29.

10. Lima M., Oakes, W. C., Ph. D, Gruender JL. (2006). Service-learning: Engineering in your community. New York: Oxford University Press.

11. Canadian Engineering Accreditation Board (2012) Accreditation criteria and procedures. Retrieved from http://engineerscanada.ca/sites/default/files/w_Accreditation_Criteria_Procedures_2012.pdf 